\title{
How Often Do You Move? Improving Student Learning in the Elementary Classroom through Purposeful Movement
}

\author{
Emily McGregor, Karen Swabey, Darren Pullen \\ Faculty of Education, University of Tasmania, Launceston, Tasmania, Australia \\ Email: Karen.Swabey@utas.edu.au
}

Received January 2015

\begin{abstract}
It is estimated that 85 percent of students in school are natural kinaesthetic learners. It has been suggested that these particular learners are not being catered to through traditional teaching practices. There is a growing body of evidence to support the connection between physical movement and increased student academic achievement. This research differs from existing literature as it focuses on teachers' inclusion of physical movement in everyday classroom learning. The aim of this research was to investigate how and why elementary school teachers incorporate movement into everyday classroom learning. Qualitatively, significant differences were found between how teachers believed they integrated movement into their everyday classroom learning, and how movement can be integrated to benefit student's engagement and academic achievement. These findings suggest that the integration of movement into everyday classroom learning significantly increases student engagement. Professional development for teachers as well as communities of practice, need to be accessible by teachers in order for them to learn how to integrate movement into their everyday classroom learning and therefore increase their students' academic achievement as well as engagement in learning.
\end{abstract}

\section{Keywords}

Elementary Education, Purposeful Movement

\section{Introduction}

There is a clear and fundamental gap in the current literature between how teachers should incorporate movement in everyday activity for their students, and how it is incorporated at the classroom level. In recent years, Australian classrooms have made the transition from chalk and talk or teacher-led classrooms, to a constructivist approach where students are encouraged to collaborate and discuss their learning with each other [1]. Although improvements are being made, there are still students whose educational needs are not being met, in particular, kinaesthetic learners [2]. There are community perceptions that learning standards have reduced in recent times, in particular, there has been much publicity surrounding Government standardised testing, specifically, National assessment program—Literacy and numeracy (NAPLAN) [3]. Many teachers feel the pressure to teach to the 
test, rather than use an holistic approach to learning [4]. The crowded curriculum is also seen as a contributing factor to the decline of achievement of learning outcomes [5]. For these reasons, some teachers may not have been catering to the needs of kinaesthetic learners. As a result of this, kinaesthetic learners have become disengaged and their academic performance has suffered [4] [6]. Research suggests that the inclusion of physical movement into children's lives does improve academic performance and levels of engagement [7] [8].

Recent research also suggests that learning is enhanced when movement is used as a strategy in the teaching process [7]. Learning is enhanced through an increase in students' level of engagement throughout everyday classroom learning [2]. Kinaesthetic learners are often left behind in class as their learning style is rarely catered for by classroom teachers [9]. Juxtaposing this, Kraft [4], believed that kinaesthetic learning styles were more effective at enhancing retention levels and engagement in elementary school students, as students are actively involved in the learning process. By encouraging students to learn kinaesthetically, teachers are breaking the routine of students sitting while learning at school. Teachers use movement to enhance student learning by engaging students in the learning, drawing on the students' interests and linking this to their planning when including movement in everyday classroom learning. Movement promotes blood flow in the body, increasing the levels of oxygen in the brain and in turn, supporting increased neural transmission and synaptic connections [10]. The above statements demonstrate the insight this research will provide to elementary classroom teachers, and also the valuable contribution kinaesthetic movements can have on students' engagement and retention of information.

The aim of this research was to investigate the reasons why teachers either incorporate or do not incorporate physical movement into their everyday classroom learning activities, and to look at the strategies they might use if they do incorporate physical movement into their teaching practices. The findings of this investigation will provide future elementary teachers with first hand, authentic insights into the specific reasons and strategies for the incorporation of physical movement in the elementary classroom; assisting elementary school teachers to feel more confident and comfortable integrating these strategies into their classroom in a range of curriculum areas to improve their students' learning. Teachers do however, need to ensure the strategies they use to incorporate physical movement into the classroom are culturally appropriate to the situation and needs of their students [11].

\section{Methodology}

A purposeful sampling style was used in this research. A school was purposefully chosen for this research due to ease of access and the location being convenient to the researchers. The school had 10 elementary school teachers; therefore all teachers from this school were invited to participate in an interview. Standard University of Tasmania ethics procedures to conduct research was obtained. Permission was sought by email from the Principal of the school to conduct the research at their school. At a nominated staff meeting the researcher informed teachers of the research and invited them to participate. Those who chose to participate were provided with an information sheet and consent form. The researcher responded to any questions the participants had at the end of the meeting. Participants were then offered a one-on-one interview appointment to discuss the research and to provide their responses to semi-structured interview questions. Participants were informed that they were free to withdraw at any time from the study without providing an explanation and that any data that could be attributed to them would be removed.

\section{Data Collection and Analysis}

The teachers were interviewed and the reasons for including or not including physical movement into their everyday classroom practice recorded; their strategies for doing this were also noted [12]. Each interview contained 18 questions that resulted in the interviews being approximately 15 minutes in duration; this was dependent on whether or not teachers used movement in their everyday classroom learning.

Through the use of a semi-structured interview schedule, all questions were given to the participants prior to the interview taking place [12]. However, this style of interview is flexible and was open for exploration of particular topics when the interviewee wished to expand upon their answer or the interviewer wished to ask an additional question. Interviews were recorded and stored digitally and the interview recordings were transcribed for reporting purposes. Confidentiality and anonymity of participants was protected through the use of assigning pseudonyms to participants in all transcripts and subsequent reports.

The interviews were recorded using a sound recorder. This was played back afterwards to organise the raw 
data and a transcript of the interview recording was made. The data was then coded into categories and themes according to the different topics. A thematic analysis was used to investigate the participants' intrinsic beliefs and to identify and analyse the data. This was then interpreted with conclusions and meanings being drawn from the transcripts. The implications for theory and practice were also selected and analysed [13].

\section{Results and Discussion}

The results and discussion are presented together. These have been amalgamated to ensure clarity of the findings and to prevent duplication of information. To comply with the ethical guidelines for this research the participant's names have been omitted and interviewees are referred to as Participant followed by the number, representing the order in which they were interviewed. Six core themes were developed from the responses participants provided to the interview questions. The themes were: use of movement, curriculum, influence of gender, integration, behaviour management and engagement.

\subsection{Use of Movement}

A key finding of the research was uncovered in this theme area. This study found that 80 percent of participants believed that they were integrating movement into everyday classroom activities, however, when they described an example of this to the researcher, they described movement being used to give students a break from learning when it is ideally used to engage students in learning. Therefore, movement was being used as a break from learning rather than as a purposeful tool to enhance learning. Eighty percent of participants used movement as a way to manage negative behaviour in their classroom or as a transition between learning activities. Participant 3 is one of these participants and added to this discussion by stating that "we tend to alternate the different activities and have a lot of transition time. So they're short and sharp, for those reasons". These teachers are neglecting to involve their students in valuable learning opportunities and in turn, preventing them from achieving the increased academic performance that the students who were actually using movement in their everyday classroom learning were reported to achieve. The two teachers who did accurately integrate purposeful movement into their everyday classroom learning reported increased student engagement as a result of this. From the participants' responses, it is clear that the majority of teachers are not using purposeful movement for the benefit of their students or their learning. It is the students who are suffering due to teachers the lack of knowledge about the benefits of purposeful movement on student engagement and academic achievement.

\subsection{Curriculum}

The theme of Curriculum determined that English was the curriculum area that was reported as having the highest frequency of integration of movement by participants. Many participants found the use of role play and other drama activities to be effective in communicating different literary texts the students were studying in class. The data from this research demonstrated the attention these primary school teachers are giving to literacy and the use of movement to engage both genders in learning to produce greater academic achievements. This data challenges findings by [14] who stated that "the chief cause of boy failure in school is literacy failure" (p. 18).

\subsection{Influence of Gender}

The Influence of gender theme confirmed a general consensus amongst interviewees, which was based on their practical experience, that boys in particular need a lot more physical body movement than girls within the classroom. There was also a belief that the inclusion of physical movement in classrooms does have a positive effect on the engagement as well as the academic performance of boys; and, pedagogies that engage boys will equally engage girls. While some participants believed that boys have a shorter attention span than girls, this was challenged by [15] who believed that if a student of either gender is sufficiently interested and challenged within their appropriate ability level, their attention span is longer. It was determined from this that both genders should be treated and taught equally in everyday classroom learning situations.

\subsection{Integration}

The theme, Integration discussed younger students enjoying the incorporation of movement because of the ele- 
ment of play that it can involve; whereas the upper elementary students did not want to be judged by their peers for actively involving themselves in the movement. It was found that if teachers embed movement into their everyday classroom learning, then students are less likely to recognise this, which was found to be neither a negative or positive aspect.

\subsection{Behaviour Management}

Behaviour management was seen by participants as a motive for the inclusion of movement into everyday classroom learning. The use of manipulatives was discussed as an effective behaviour management tool for classrooms of a particular context. Reference [16] defined manipulatives as objects that promote the use of several senses as they can be touched, moved about, rearranged, and otherwise handled by students. Some participants believed that if students are engaged in what they are doing, there will be no negative behaviour to manage.

\subsection{Engagement}

Engagement was the reason most interviewees gave for their use of movement in the classroom. Participants who incorporated movement into their everyday classroom learning reported significant retention of information by their students as well as increased academic performance, which was consistent with the research findings of [2].

\section{Conclusion and Recommendations}

It was concluded that teachers often use movement in their classrooms as a tool for behaviour management or to engage students in learning activities. From the data collected, analysed and discussed, it was clear that elementary school teachers, at least in this specific Independent school, need professional development to understand the opportunities that the inclusion of movement can make in their everyday classroom in terms of students learning and behaviour management strategies. Teachers also need to be given strategies on how to successfully implement movement into varying areas of the curriculum. Kinaesthetic learners need to become a focus for teachers in the $21^{\text {st }}$ century. Deeper research in this area would assist these learners to achieve to the best of their abilities.

Changes need to be made to the educative process of teachers. Teachers need to be given the opportunity to attend professional development conferences such as Rich Allen's who Participant 2 stated they had attended, to learn strategies for how to incorporate movement into their everyday classroom learning. A community of practice model may be one way that teachers are able to support each other through this process [17]. Through this process, however, it is imperative for teachers to be made aware of the above benefits to student's engagement and academic performance with the inclusion of movement in everyday classroom learning. Stronger links need to be made between theory and practice. Specifically, greater research needs to be undertaken in an attempt to bridge the absence between theory and practice, particularly when strategies such as these have proven positive effects on students and their academic performance in the classroom. Teachers need to become aware of theorists and pioneers in the field of integrating movement into classroom learning, such as [18]. An approach to aid this would be the use of peer support and the establishment of a community of practice [17].

A larger study needs to be undertaken with a larger sample size and a broader range of participants from both Independent and Government schools. Although for the purposes of this research, 10 participants was an adequate number to gather valuable insights into the research area, for a definitive study more participants need to be interviewed. The interview questions used in this research should be reflected upon further by the researcher as well as adapted and refined to ask participants more specific as well as broader questions when necessary. By broadening the investigation, other strategies teachers use to incorporate movement may be uncovered.

\section{References}

[1] Whitton, D., Sinclair, C., Barker, K., Nanlohy, P. and Nosworthy, M. (2004) Learning for Teaching, Teaching for Learning. Thomson Social Science Press, Melbourne.

[2] Spielmann, C. (2012) The Effects of Movement Based Learning on Student Achievement in the Elementary School Classroom. RevaRitz Shop, Hartford. 
[3] Australian Curriculum, Assessment and Reporting Authority [ACARA] (2014) National Assessment Program—Literacy and Numeracy (NAPLAN). http://www.nap.edu.au/naplan/naplan.html

[4] Tinning, R., McCuaig, L. and Hunter, L. (2006) Teaching Health and Physical Education in Australian Schools. Pearson, Frenchs Forest.

[5] Reynolds, R. (2012) Teaching History, Geography and SOSE in the Primary School. 2nd Edition, Oxford University Press, South Melbourne.

[6] Kraft, R. (1990) Experiential Learning. University Press, Denver.

[7] Smith, P. and Pellegrini, A. (2013) Learning through Play. http://www.child-encyclopedia.com/documents/Smith-PellegriniANGxp2.pdf

[8] Wade, V. (2008) Active Intervention: Kinesthetic Learning Style Leavens the Lump of Student Achievement of Autistic Students. Ph.D. Thesis, Capella University, Minneapolis.

[9] Whitmire, R. (2010) Why Boys Fail. American Management Association, New York.

[10] Ratey, J. (2008) Spark: The Revolutionary New Science of Exercise and the Brain. Little Brown, New York.

[11] Ashman, A. and Elkins, J. (2012) Education for Inclusion and Diversity. 4th Edition, Pearson, Frenchs Forest.

[12] O’Leary, Z. (2010) The Essential Guild to Doing Your Research Project. Sage, London.

[13] Saldana, J. (2009) The Coding Manual for Qualitative Researchers. Sage, London.

[14] McBride, B. (2011) Closing the Achievement Gap: Teaching to Gender Differences. https://www.nassp.org/tabid/3788/default.aspx?topic=Closing the Achievement Gap Teaching to Gender Differenc $\underline{\text { es }}$

[15] Moyer, K. and von Haller Gilmer, B. (1954) The Concepts of Attention Spans in Children. The Elementary School Journal, 54, 464-466. http://dx.doi.org/10.1086/458623

[16] Kennedy, M. (1986) A Rationale. Arithmetic Teacher, 33, 6-7.

[17] Wenger, E. (1998). Communities of Practice: Learning Meaning and Identity. Cambridge University Press, Cambridge. http://dx.doi.org/10.1017/CBO9780511803932

[18] Gardner, H. (1983). Frames of Mind: The Theory of Multiple Intelligences. Basic Books, New York. 